[Research Paper]

\author{
농연에 의한 드론 수신 전파 감쇠에 관한 연구 \\ 김태동· 염인수 ${ }^{* \dagger}$ \\ 국립소방연구원 대응기술연구실 연구원, "국립소방연구원 대응기술연구실 연구원
}

\title{
Attenuation of Microwaves Received From a Drone Owing to Smoke Obscuration
}

\author{
Tae-Dong Kim $\cdot$ In-Su Yeom ${ }^{*+}$
}

Researcher, Department of Resilience Enhancement Technology, National Fire Research Institute,

${ }^{*}$ Researcher, Department of Resilience Enhancement Technology, National Fire Research Institute

(Received October 26, 2020; Revised November 22, 2020; Accepted November 23, 2020)

\section{요 약}

본 논문은 농연에 의한 드론 수신 전파 감쇠의 상관성을 분석하였다. 수신되는 신호 감도를 분석하기 위해 스펙트 럼 분석기와 지향성 안테나를 적용하였고, 실 화재 감식 훈련장에서 연기 층 진입 전후 각 $1 \mathrm{~min}$ 간 상대적인 평균수 신 강도를 측정하였다. 사용된 드론은 $2.4 \mathrm{GHz} 2.48 \mathrm{GHz}$ 에서 동작하며 연기층 집입 전 수신되는 전파강도는 - 39.3 $\mathrm{dBm}$ 으로 조정 신호 및 영상데이터 수신이 가능함을 확인하였다. 그러나 연기층에 진입했을 때 전파강도는 $-47 \mathrm{dBm}$ 으로 낮아져 신호의 차단 현상이 발생하였고, 농연에 의해 약 $7.7 \mathrm{dBm}(5.9 \mathrm{~mW})$ 의 감쇠를 보여 주었으며 전파감쇠 에 의해 통신장애가 나타나고 있음을 알 수 있었다. 이를 통해 화재 시 발생하는 농연에 의해 수신되는 전파가 감쇠 되며 결과적으로 통신 성능을 열화시켜 드론 운영에 영향을 주고 있음을 확인하였다.

\begin{abstract}
The objective of this study is to analyze the effect of smoke obscuration on the signal sensitivity of microwaves received from a drone. A spectrum analyzer and a directional antenna were employed for analyzing the received signal sensitivity and measuring the mean received power, both before and after the drone entered the smoke layer for one min in the fire training area. The drone operated in the range of $2.4 \mathrm{GHz}$ to $2.48 \mathrm{GHz}$. It is found that the received power before entering the smoke layer is $-39.3 \mathrm{dBm}$, at which signals and image data can be received. However, upon entering the smoke layer, the received power is reduced to $-47 \mathrm{dBm}$, at which signals and image data cannot be received. Hence, the received power undergoes an attenuation of approximately $7.7 \mathrm{dBm}(5.9 \mathrm{~mW})$ owing to smoke obscuration, which causes communication outage. Based on this study, it can be concluded that the received power undergoes attenuation owing to smoke obscuration during fires. Furthermore, if a communication problem occurs due to microwave attenuation, it affects the drone's operation.
\end{abstract}

Keywords : Microwave, Firefighting drone, Smoke obscuration, Full-scale fire experiment, Received power

\section{1. 서 론}

최근 드론 관련한 산업은 날로 발전하고 있고 이에 따라 드론의 활용수요가 크게 증가하고 있다. 특히 공공 이익의 가치를 창출하는 업무를 위해 공공기관 등에서 다수의 드 론을 활용하고 있다. 더욱이, 소방기관 및 재난 안전 부처 에서는 방사능, 화재, 붕괴, 화학, 자연재난 등 인적·물적 피해를 최소화를 위해 드론 등의 첨단기술을 활용하고 있
으며, 주로 전술 작전에 도움이 되도록 재난현장 관제 목적 으로 활용하고 있다 ${ }^{(1)}$.

재난현장에서 주변 전파간섭으로 인해 영상송출이 원활 하지 않은 등의 문제가 다분하다. 일반적으로 드론은 무선 전파를 활용하여 조종 신호 및 영상 데이터를 송·수신하며, 전파되는 매질에 따라 강도 및 전파 거리가 변화한다. 화재 현장에서 주로 활용되는 드론의 통신은 Industrial Scientific and Medical (ISM) Band의 주파수(2.4 2.48 GHz)대역을 사

${ }^{\dagger}$ Corresponding Author, TEL: +82-41-559-0520, FAX: +82-41-541-1108, E-Mail: insu81@korea.kr

(c) 2021 Korean Institute of Fire Science \& Engineering. All right reserved. 
용한다. ISM Band는 단일 대역의 주파수가 아닌 여러 구간 을 걸쳐 골고루 분포된 주파수를 사용하며, 비면허 대역으 로 무선국 허가 없이 자유롭게 사용할 수 있다는 큰 장점 이 있다. 그러나 ISM Band의 동일대역을 사용하는 통신장 비 간에 간섭으로 인해 통신감쇠가 발생할 수 있으며, 재난 현장에서 드론 운용 간 영상-조종 신호 차단으로 인해 2차 사고로 이어질 가능성이 존재하고, 운용 가능 전파거리가 감소, 영상 중계 오류 등 기술적 한계가 존재한다 ${ }^{(2-4)}$.

특히 화재현장에서 드론을 활용할 경우 농연에 의한 전 파 감쇠현상이 발생할 수 있다. 전파 특성상 무손실의 공기 중에 통과하는 전파에 비해 유전체나 농연 등과 같은 입자 가 존재하는 공기층을 통과할 때 대기 손실과 유전층에서 발생하는 분극현상에 의한 손실이 발생한다 ${ }^{(5)}$. 더불어 매질 변화에 의한 굴절, 산란, 회절에 의한 손실이 나타나며, 화 재의 화염 영역에서 발생하는 유도 플라즈마 형성에 의한 전자기 에너지의 손실은 전자기파의 감쇠를 야기한다(6,7).

이에 본 연구는 화재 상황에서 발생하는 전파 감쇠에 따 라 통신 성능 열화를 야기하여 드론 운용에 영향을 주고 있음을 확인하기 위해 전파감쇠의 강도를 정량적으로 분석 하고자 한다.

\section{2. 본 론}

화재연기 발생 시 드론의 전파 상관성에 대한 오류 현상 을 확인하기 위해 전남 소방본부에서 진행하는 실물화재감 식 대회와 병행하여 사전실험을 진행하였다. 건물 내부에 착화 후 약 5 분 경과하였을 때 유리창이 깨지며 연기가 분 출되면서 Figure 1 (a) 처럼 $2 \mathrm{~s}$ 가량 영상신호가 매끄럽지 못한 현상이 생겼으며, 착화 후 약 $8 \mathrm{~min}$ 경과 시 열이 순 식간에 전달되어 Flash over 현상이 발생함에 따라 다량의 연기가 분출되면서 Figure 1 (b)처럼 드론 영상의 끊김으로 인해 관제 모니터링이 불가하였다. 이를 통해 Flash over 현 상 발생 시 다량의 연기분출로 인해 드론의 영상 및 음성 신호 정보가 잘 전달 되지 못하는 것을 알 수 있었다.

해당 현상에 대한 전파감쇠의 강도를 정량적으로 분석 하고자 전파측정기와 지향성 안테나를 준비하여 추가실험 을 진행하였다. 실험 구성 및 설계 방법은 다음과 같다.

\section{1 실험 구성 및 설계}

Figure 2 는 제안된 측정조건에 대한 기본적인 구성을 보 여준다. 그림에서와 같이 드론에서 송신되는 신호를 수신 하여 전파강도를 측정하였으며, 화재발생 후 농연 분출에 따른 전파 강도를 비교하였다.

자유공간을 통과하는 전파는 동일 위상의 균일 평면파 를 의미한다. 전파의 평면파 조건을 만족하기 위해서는 원 거리장 이상의 송·수신 간격을 유지해야 한다.

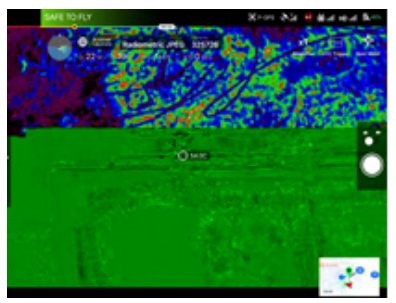

(a)

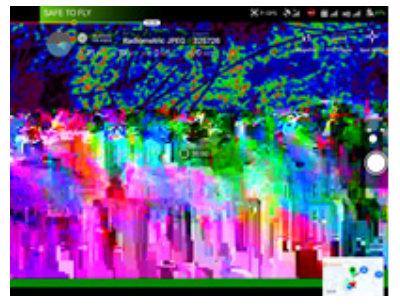

(b)
Figure 1. Video signal dissipation due to fire smoke, (a) in case of window broke (b) in case of flash over.

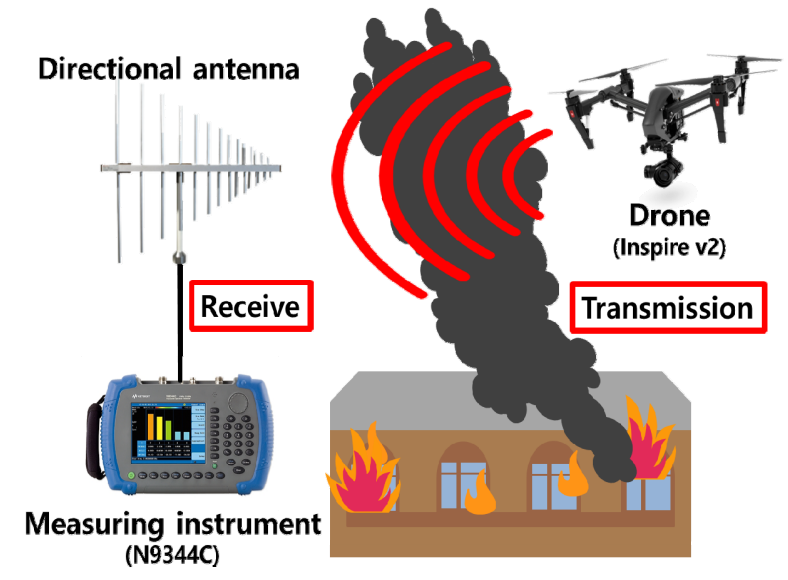

Figure 2. Setup for measuring of microwave attenuation.

$$
\text { Far field }(\text { 원거리장 })=\frac{2 D^{2}}{\lambda}
$$

여기서, 여기서 $\mathrm{D}$ 는 안테나의 직경, $\lambda$ 는 공진주파수의 파장을 의미한다. 이에 본 연구에서는 원거리장(Far field) 영역의 최소 이격 거리를 구성하기 위해 $5 \mathrm{~m}$ 이상 이격하 여 측정하였다 ${ }^{(8)}$. 또한, 본 실험을 위해 충분한 이득을 보여 주는 지향성 안테나와 수신되는 전파의 크기를 측정할 수 있는 스펙트럼 분석기를 사용하였다.

수신부의 사용된 안테나는 A-INFOMW사의 대수 주기 안테나로 $100 \mathrm{MHz} 3000 \mathrm{MHz}$ 의 대역폭을 가지며 $6 \mathrm{dBi}$ 이 상의 충분한 이득을 보여 주는 지향성 안테나이다. 그리고 Keysight 사의 $\mathrm{N} 9344 \mathrm{C}$ 장비를 이용하여 수신되는 전력 크 기를 측정하였다. 또한, 송신부의 드론은 $\mathrm{D}$ 사의 Inspore 기 체를 운용하였다. 동작 주파수는 $2.4 \mathrm{GHz} 2.48 \mathrm{GHz}$ 이고 최대 전송 거리는 $2 \mathrm{~km}$ 이다. 본 연구는 드론의 동작 주파 수 범위 이상의 $2.3 \mathrm{GHz} 2.6 \mathrm{GHz}$ 대역까지 측정하였으며 실 화재 실험의 측정거리는 $150 \mathrm{~m}$ 이내에서 진행하였다 ${ }^{(9)}$.

Figure 3은 실제 화재환경에서의 농연에 따른 드론 수신 전파 감쇠를 측정할 수 있는 구성을 보여준다. 본 연구의 실험은 강원소방학교 화재감식 훈련장에서 실행하였으며 훈련장내부에서 인위적으로 착화하여 화재를 발생시켰다. 화재 발생 후 농연에 따른 수신 감쇠를 비교하기 위해 


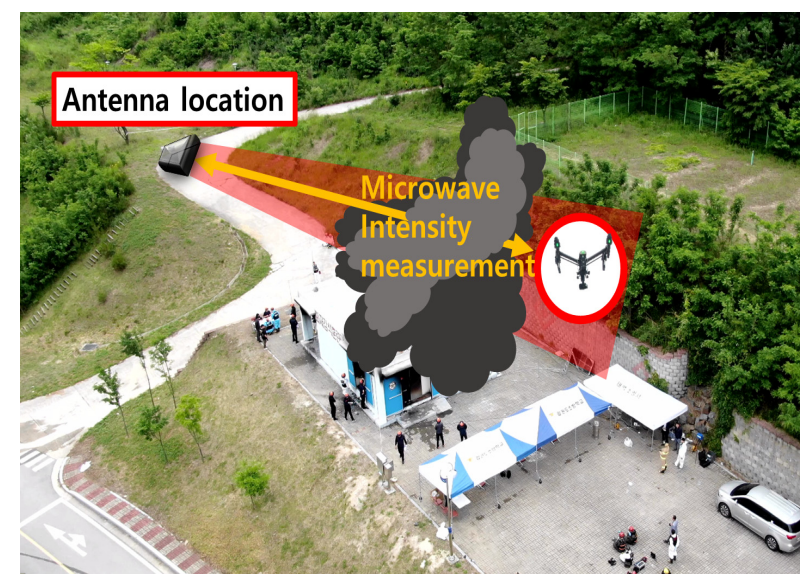

Figure 3. The measurement environment with real scale fire.

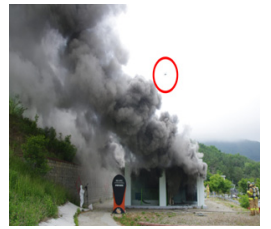

(a)

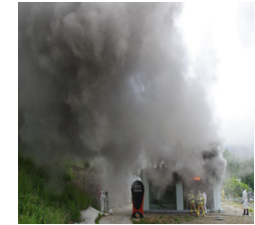

(b)

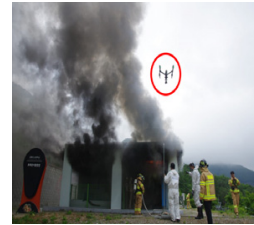

(c)
Figure 4. The photo of entering the smoke layer, (a)before (b) entering (c) after.

Figure 4에서와 같이 연기 층 진입 전(a), 연기 층 진입(b) 그리고 연기 층 통과 후(c) 의 전파강도를 각 $1 \mathrm{~min}$ 간 측정 하였고 드론 운용을 통해 전파강도 감쇠에 따른 통신 성능 을 수치로 비교하였다.

\subsection{Flash over 진행 양상}

Flash over 에서 분출되는 농연의 정량적인 지속시간을 측정하기 위해 시간대 별로 온도를 측정하였다. 건물 실내 (사무실)에 착화를 시작하였으며, 착화 후 $4 \mathrm{~min}$ 경과하였 을 때 실외로 연기가 피어오르기 시작하였다. Figure 5는 실내(사무실) 화재 시 열전대(Thermocouple)의 온도 측정 결과를 보여준다. 온도 측정 결과 08:27 08:35경 깨진 유리 창문을 통해 연기가 다량 분출되었으며 Flash over 지속시 간은 약 $8 \mathrm{~min}$ 간 진행되었다. 화재에 의한 연기 분출량이 가장 많은 영역대에 드론을 운용하여 전파감쇠 강도를 측 정해야 되기 때문에 유리창이 깨진 시점에서 드론을 운용 하기 시작하였다.

\section{3 전파 측정 결과}

Figure 6은 화재 발생 전 원거리장 $(5 \mathrm{~m})$ 에서 수신안테나 와 드론간의 전파강도를 측정하였다. 측정된 전파 강도는 평균 $-17.6 \mathrm{dBm}$ 이다. Figure 7은 드론 이륙 후 연기 층 진입 전 수신되는 전파 강도를 보여준다. 측정된 전파 강도는 평 균 -39.9 dBm를 보여 주었으며, 조종 신호 및 영상 데이터 수신이 가능하였다. Figure 8은 연기 층에 진입했을 때 전

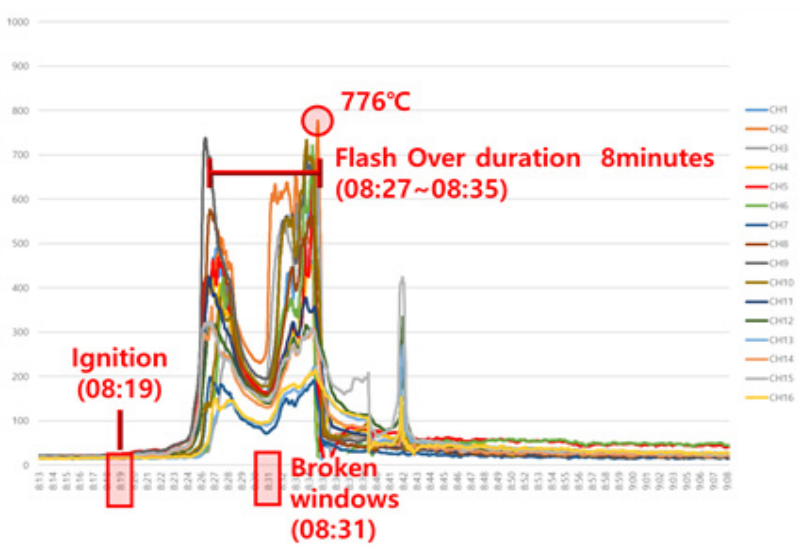

Figure 5. The measurement result of THCP temperature in fire.

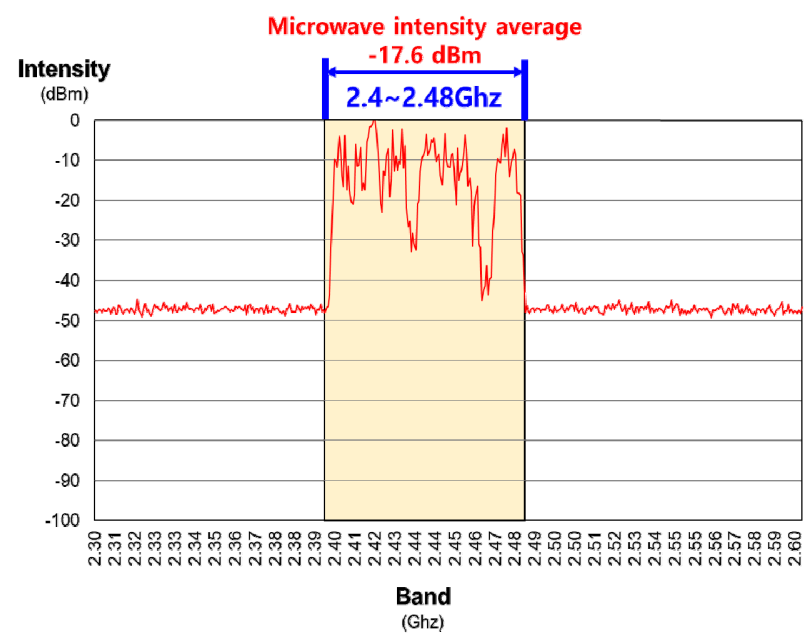

Figure 6. Measurement result of received power at $5 \mathrm{~m}$ in air.

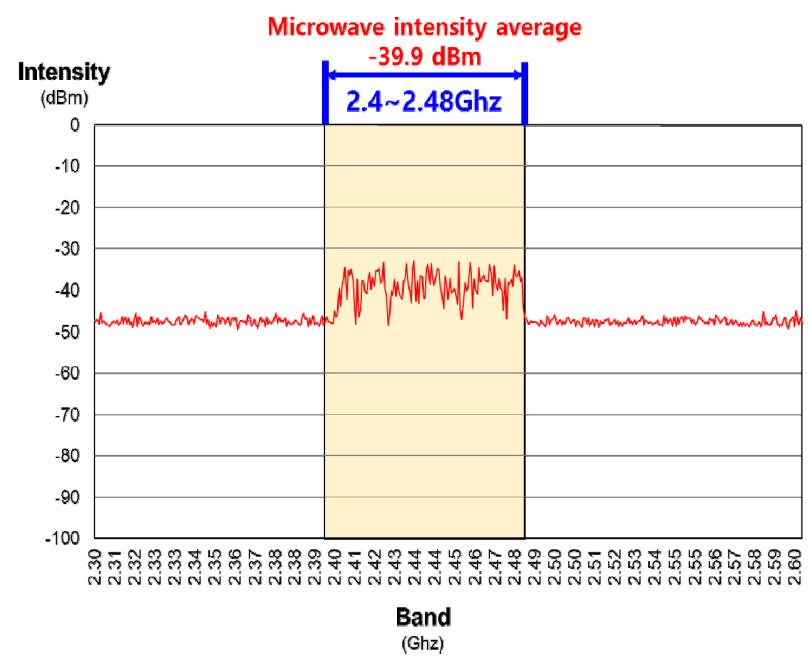

Figure 7. Received power before entering the smoke layer.

파강도를 보여주며, 측정된 전파강도는 평균 $-47 \mathrm{dBm}$ 으로 낮아짐을 알 수 있다. 이때, 감소된 전파강도의 의해 약 1 


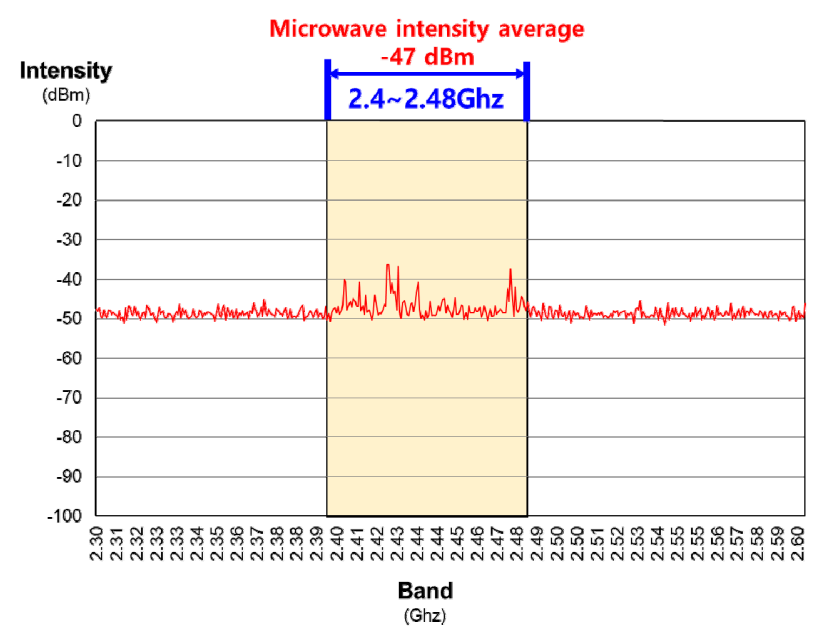

Figure 8. Received power in entering the smoke layer.

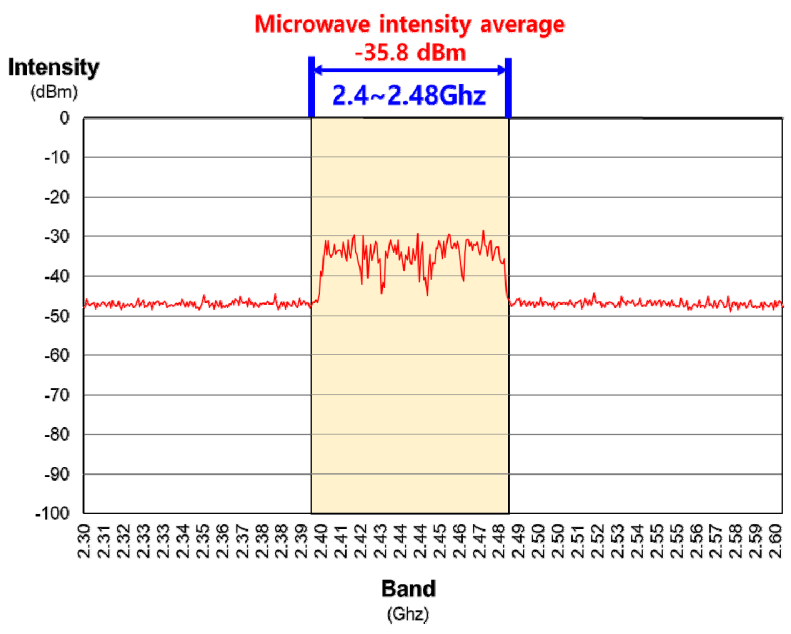

Figure 9. Received power after entering the smoke layer.

３ s간 간헐적인 영상데이터가 수신 차단 현상이 발생하였 다. 마지막으로 Figure 9는 연기 층을 완전히 통과한 이후에 전파강도를 보여준다. 측정된 전파강도는 평균 $-35.8 \mathrm{dBm}$ 이며, 조종 신호 및 영상데이터 수신이 원활하게 되고 있음 을 확인하였다.

\section{3. 결 론}

본 실험은 농연에 의한 드론 수신 전파 감쇠의 상관성을 분석하였다. 실 화재 실험을 통해 분석하였으며, 화재 발생 후 연기층 진입 전 후 측정한 결과 $-39.3 \mathrm{dBm}$ 에서 $-47 \mathrm{dBm}$ 으로 감소하는 것을 확인하였다. 이를 통해 화재에 의한 연 기발생 시 전파강도가 감소하며 통신 성능이 열화되어 드 론 수신에 영향을 주고 있음을 확인하였다. 따라서 주택의 화재상황에서 드론을 활용하고자 하는 경우 화재확산을 고
려하여 연기층으로 접근하지 않도록 피하여 적절한 관제가 필요할 것으로 판단된다.

본 연구는 실험적으로 농연과 전파감쇠에 관한 연관성 을 제시하였으며 이를 통해 화재현장 드론 운용 시 관제 효율성을 높일 수 있을 것으로 생각된다. 향후 일선서에서 활용하는 상용제품의 드론을 수요조사 후 활용빈도가 높은 기체모델을 선정하여 추가 실험이 진행되야 하며, 연기농 도별로 전파강도를 측정하여 농연에 의한 전파 감쇠의 기 준을 명확하게 파악하기 위한 추가 연구가 필요할 것으로 사료된다.

\section{후 기}

본 연구는 소방청 소방대응력 향상을 위한 연구개발지 원사업(1761001720)의 연구비 지원을 받아 수행되었습니다.

\section{References}

1. H. Y. Gyo, "Service Design for Using the Drone in the Early Stage Fires of Dense Residential Areas", The Korea Contents Association, Vol. 19, pp. 111-121 (2019).

2. H. U. Kim, G. S. Kang and B. S. Lee, "R\&D and Standardization Trends on Control and Non-payload Communication for Unmanned Aircraft Systems. ETRI", Electronics and Telecommunications Trends, Vol. 33, No. 3, pp. 70-77 (2018).

3. G. G. Wang, B. S. Lee and J. Y. Ahn, "Communication and Security Technology Trends in Drone-assisted Wireless Sensor Network. ETRI", Electronics and Telecommunications Trends (2019).

4. http://store.dji.com

5. D. M. Pozer, "Microwave Engineering", Fourth Edition, John Wiley, \& Sons Ltd., USA (2020).

6. K. M. Mphale, P. V. C. Luhanga and M. L. Heron, "Microwave Attenuation in Forest Fuel Lames", Combustion and Flame, Vol. 154, No 4, pp. $728-739$ (2008).

7. J. A. Boan, "Radio Propagation in Fire Environments", $\mathrm{PhD}$ Thesis (2009).

8. I. S. Yeom, J. H. Choi, S. S. Kwoun, B. J. Lee and C. W. Jung, "Analysis of RF Front-End Performance of Reconfigurable Antennas with RF Switches in the Far Field", International Journal of Antennas and Propagation, Vol. 2014, Article ID 385730, pp. 1-14 (2014).

9. C. A. Balanis, "Antenna Theory: Analysis and Design", John Wiley \& Sons Ltd, Chichester, UK (2005). 